\begin{tabular}{|c|l|}
\hline Title & Evaluating metrics derived from Landsat 8 OLI imagery to map crop cover \\
\hline Author(s) & Sonobe, Rei; Y amaya, Y uki; Tani, Hiroshi; W ang, X iufeng; Kobay ashi, Nobuy uki; Mochizuki, Kan-ichiro \\
\hline Citation & $\begin{array}{l}\text { Geocarto International, 34(8), 839-855 } \\
\text { https://doi.org/L0.1080/10106049.2018.1425739 }\end{array}$ \\
\hline Issue Date & 2019-07-03 \\
\hline Doc URL & http://hdl.handle.net/2115//8799 \\
\hline Rights & $\begin{array}{l}\text { This is an A ccepted Manuscript of an article published by Taylor \& Francis in Geocarto International on 3 Jul. 2019, } \\
\text { available online: http:/www.tandfonline.com/doi/abs/10.1080/10106049.2018.1425739. }\end{array}$ \\
\hline Type & article (author version) \\
\hline File Information & Manuscript_TGEI-2017-0343.pdf \\
\hline
\end{tabular}

Instructions for use 


\section{Evaluating metrics derived from Landsat 8 OLI imagery to map crop cover}

Developing techniques are required to generate agricultural land cover maps to monitor agricultural fields. Landsat 8 Operational Land Imager (OLI) offers reflectance data over the visible to shortwave-infrared range. OLI offers several advantages, such as adequate spatial and spectral resolution, and 16 day repeat coverage, furthermore, spectral indices derived from Landsat 8 OLI possess great potential for evaluating the status of vegetation. Additionally, classification algorithms are essential for generating accurate maps. Recently, multi-Grained Cascade Forest, which is also called deep forest, was proposed, and it was shown to give highly competitive performance for classification. However, the ability of this algorithm to generate crop maps with satellite data had not yet been evaluated. In this study, the reflectance at 7 bands and 57 spectral indices calculated from Landsat 8 OLI data were evaluated for its potential for crop type identification.

Keywords: crop; deep forest; Landsat 8; random forests; reflectance; spectral indices

\section{Introduction}

Crop specific land cover greatly influences soil and water quality, and information about them are helpful for evaluating increases in solar energy harvesting and carbon flux into the soil (Dabney et al., 2001). Furthermore, since statistics related to the study of agricultural fields could be useful information for solving issues concerning food insecurity and poverty (Khan et al., 2010), some local governments in Japan have been making efforts to manually categorise field properties such as crop type and location. Developing techniques to generate agricultural land cover maps has been required and efforts to address recurrent problems in remote sensing have been undertaken (Sonobe et al., 2017c).

Landsat series data have been shown to be suitable for land characterisation activities due to its spatial, spectral, and radiometric data quality (Wulder et al., 2008, 
Vogelmann et al., 2016). Thus, the data acquired from Landsat are also useful for assessing the condition of vegetation like leaf area index (Dahms et al., 2016, Masemola et al., 2016) or chlorophyll content (Pastor-Guzman et al., 2015) and tracing vegetation phenology (Elste et al., 2015). In particular, spectral indices derived from reflectance data acquired from optical sensors have been widely used to assess various properties of vegetation or soil (Guan et al., 2017, Jin et al., 2017, Sonobe et al., 2018), and a vast number of spectral indices could be calculated from Landsat 8 Operational Land Imager (OLI) data. Although some of them possess great potential for improving the classification accuracies, they have not been fully evaluated in previous studies. In this study, 57 published indices and original reflectance data sources were evaluated to classify six crop types, including beans, beetroot, grass, maize, potato, and winter wheat, which are dominant crops over the western Tokachi plain, Hokkaido, Japan.

Classification and regression trees (CART) is an attractive option to generate agricultural land cover maps and the US and Canada have successful ag-specific land cover monitoring programs based on this algorithm (Boryan et al., 2011; Fisette et al., 2013). Furthermore, the US Geological Survey distributed the National Land Cover Database (NLCD), which is also based on CART, and known as a high quality land cover monitoring program. Besides CART, random forests (RF) is one extremely successful algorithm used as a general-purpose classification and regression method (Biau and Scornet, 2016), and some previous studies show the advantages of RF classification using optical imagery (Immitzer and Atzberger, 2014, Sonobe et al., 2014). RF is an ensemble learning technique that builds multiple CART based on random bootstrapped samples of training data (Breiman, 2001), and one of its advantages is to have few hyperparameters to optimise. Furthermore, it can offer good predictions and quantify each input variable based on an importance measure, 
regardless of large sample sizes or vast numbers of input variables such as the expenses of irregular samples including outliers and noise (Breiman, 2001, Cutler et al., 2007).

Recently, gcForest (multi-Grained Cascade Forest), which is also called deep forest, was proposed (Zhou and Feng, 2017). A cascade structure composed of RF is employed in this algorithm, and each cascade level receives feature information processed by its preceding level and outputs its processing results to the next level; its highly competitive performance has been shown for classification (Zhou and Feng, 2017). However, the use of gcForest to generate crop maps with satellite data has not yet been evaluated. Therefore, the potential of gcForest was also evaluated in this study.

The main targets of this study were (1) to select the optimal metrics for identifying crops based on comparing original reflectance values at 7 bands and 57 published indices derived from Landsat 8 OLI data and (2) to evaluate the performance of gcForest for crop cover classification.

\section{Materials and Methods}

\subsection{Study area}

The study was conducted using Landsat 8 operational land imager (OLI) data acquired over the western Tokachi plain, Hokkaido, Japan (Figure 1, $142^{\circ} 42^{\prime} 51^{\prime \prime}$ to $143^{\circ} 08^{\prime} 47^{\prime \prime}$ E, $42^{\circ} 43^{\prime} 20^{\prime \prime}$ to $43^{\circ} 07^{\prime} 24^{\prime \prime} N$ ). Figure 2 represents the weather conditions in 2016 ; the average monthly temperatures were $8.3-21.8^{\circ} \mathrm{C}$ and monthly precipitation was $12.0-$ $94.5 \mathrm{~mm}$ during the cultivating period (May to October) (Japan Meteorological Agency, 2017). Six crop types, including beans, beetroots, grasses, maize, potatoes, and winter wheat, are mainly cultivated. The mean size of the fields is 2.54 ha (the maximum area is 18.21 ha and the smallest area is $0.05 \mathrm{ha}$ ).

< Figure 1. The study area and Landsat 8 OLI data acquired on 7 July, 2016.> 
< Figure 2. Weather conditions in 2016.>

The cultivation calendar for the crops in this study area is shown in Table 1. Seeding of winter wheat was conducted in September 2015, and the harvesting period was late July to early August. Seeding or transplanting of beetroots and potatoes was conducted in late April to early May 2016, and seeding of maize and beans was conducted in mid-May 2016. The harvesting period was late August to September for potatoes and maize, late September to early November for beans. and November for beetroots. The first harvest was in late June to early July, and the second was in late August for grasses.

$<$ Table 1. Cultivation calendar for the crops. $>$

\subsection{Satellite data}

The Landsat-8 OLI data were acquired on 20 May, 7 July and 24 August 2016. The data, which had been spatially orthorectified by the U.S. Geological Survey, were downloaded from EarthExplorer (https://earthexplorer.usgs.gov/). The whole processing workflow is illustrated in Figure 3.

< Figure 3. Overview of the data processing.>

ENVI image analysis software version 5.3 and the Fast Line-of-sight Atmospheric Analysis of Spectral Hypercubes (FLAASH) algorithm (Matthew et al., 2000) were applied to carry out the atmospheric correction of the imagery, and the reflectance values of bands 1-7 were calculated.

The 57 published spectral indices were evaluated for their potential for crop classification (Table 2). A number of indices based on reflectance in the visible or near infrared domain have been proposed to evaluate the properties of vegetation, such as chlorophyll content (Miura et al., 1988, Karnieli et al., 2001). In some indices, the reflectance of shortwave infrared was integrated to cancel the effect of atmosphere, but 
this domain has also been proposed to evaluate photosynthesis ability (Serbin et al., 2012) and MVI (Thenkabail et al., 2002), NDSI (Allen et al., 1969), and SLAVI (Lymburner et al., 2000). Some indices developed for estimating minerals (Rowan and Mars, 2003, Volesky et al., 2003) were also assessed in this study.

$<$ Table 2. Spectral indices used in this study. $>$

Reference data in a polygon shape file, which included attribute data such as crop type, were provided by Tokachi Nosai (an organization involved in agricultural insurance which supports farmers after natural disasters and calculates the statistics related the regional agricultural industry). Based on this polygon shape file, reflectance values for the centre of the fields were extracted to avoid selecting training pixels from the edge of a field.

\subsection{Agricultural crop classification}

A total of 11900 fields (2169 beans fields, 1527 beetroot fields, 2089 grasslands, 813 maize fields, 2066 potato fields and 3236 winter wheat fields) covered the areas of interest in 2016 and average values of the reflectance values at Band 1-7 were calculated for the fields. After that, a stratified random-sampling approach was applied to divide all the reflectance data into three groups including training (50\%), validation (25\%), and test data (25\%) (Hastie et al., 2009).To apply this strategy, the reflectance data over 11900 fields were divided into 6 groups based upon crop types and, 50\% of the fields were selected as training data, which were used for generating classification models, based on random number for each group. Next, $50 \%$ of the remaining fields was selected as validation data, which were used for optimizing hyperparameters of machine learning algorithms. Finally, the last group were used as test data for evaluating classification results. This procedure was repeated ten times to give more robust results. In this study, to evaluate the performance of gcForest for crop type 
classification, experimental comparisons were conducted among CART, RF, and gcForest.

\subsubsection{Separability assessment}

Before classification, statistical separabilities of original reflectance values among crop types or spectral indices calculated from Landsat 8 OLI data were evaluated based on Jeffries-Matusita (J-M) distance (Richards, 1999); a J-M distance value of greater than 1.9 means good separation, and a value between 1.7 and 1.9 means fairly good separation.

\subsubsection{Classification algrithm}

CART has been used for building a decision tree (Breiman et al., 1984). Each node of decision trees built by CART always have only two child nodes, and the Gini index (Gini coefficient) is used for assessing the purity measure in building a decision tree. RF is an ensemble learning technique that builds multiple CART using random bootstrapped samples from the training data (Breiman, 2001). The output is determined by a majority vote from the CARTs. Generally, the number of trees (ntree) and the number of variables used to split the nodes (mtry) are tuned to increase performance of the RF classification. However, the best split for a node can increase classification accuracy (Ishwaran and Kogalur, 2007, Ishwaran et al., 2008, Sonobe et al., 2017b); thus, the minimum number of unique cases in a terminal node (nodesize), the maximum depth of tree growth (nodedepth), and the number of random splits (nsplit) were also tuned in this study. The variable importance (VIMP) was calculated when a classification model was used to evaluate how much worse the prediction would be without that variable when RF was applied (Ishwaran, 2007). Recently, inspired by representation learning in deep neural networks, gcForest, which generates a deep forest 
ensemble using a cascade structure for representation learning, was proposed; Zhou and Feng (2017) have shown that it has great abilities for image categorization, face recognition, music classification, and so on, although it has much fewer hyperparameters than deep neural networks.

\subsubsection{Accuracy assessment}

Classification maps have been assessed by a confusion matrix or error matrix (Story and Congalton, 1986). The quantity disagreement (QD) and allocation disagreement (AD) (Pontius and Millones, 2011) were used for assessing the classification accuracies based on the confusion matrices. The proportion of fields that are crop i based on the classification results but are crop j based on the correct data $\left(\mathrm{P}_{\mathrm{ij}}\right)$ is calculated using the following equation:

$$
P_{i j}=W_{i} \frac{n_{i j}}{n_{i+}}
$$

where $\mathrm{W}_{\mathrm{i}}$ are the fields classified as crop $\mathrm{i}$ and $\mathrm{n}_{\mathrm{ij}}$ is the number of fields classified as crop i according to the classification results but are crop j according to the correct data. $\mathrm{n}_{\mathrm{i}^{+}}$is the row totals of the confusion matrix. In this case, AD and QD were calculated using the following equations:

$$
\begin{aligned}
& A D_{i}=2 \min \left(p_{i+}, p_{+i}\right)-2 p_{i i} \\
& \mathrm{AD}=\frac{1}{2} \sum_{i=1}^{N_{c}} A D_{i} \\
& Q D_{i}=\left|p_{i+}-p_{+i}\right| \\
& \mathrm{QD}=\frac{1}{2} \sum_{i=1}^{N_{c}} Q D_{i}
\end{aligned}
$$

where $\mathrm{N}_{\mathrm{c}}$ is the number of crop types, $\mathrm{p}_{\mathrm{i}+}$ and $\mathrm{p}_{\mathrm{e}}$ are the row and column totals of the confusion matrix, $\mathrm{AD}_{\mathrm{i}}$ is the allocation disagreement for crop $\mathrm{I}$, and $\mathrm{QD}_{\mathrm{i}}$ is the quantity disagreement for crop i. Finally, the sum of $\mathrm{QD}_{\mathrm{i}}(\mathrm{QD})$ and $\mathrm{AD}_{\mathrm{i}}(\mathrm{AD})$ are obtained. The 
total disagreement can be evaluated based on the sum of QD and AD (Pontius and Millones, 2011).

Overall accuracy (OA), producer’s accuracy (PA), and user’s accuracy (UA) were also calculated because they are commonly used for accuracy assessments.

$$
\begin{aligned}
& \mathrm{OA}=\sum_{i=1}^{N} p_{i i} / \mathrm{N} \\
& \mathrm{PA}=p_{i i} / R_{i} \\
& \mathrm{UA}=p_{i i} / C_{i}
\end{aligned}
$$

where $\mathrm{N}$ is the number of fields, $\mathrm{R}_{\mathrm{i}}$ and $\mathrm{C}_{\mathrm{i}}$ represent the total number of crop $\mathrm{i}$ in the correct data and the total number from the classification results, respectively. OA is the total classification accuracy. PA is calculated by dividing the number of correctly classified fields for each crop type by the number of reference fields. UA is calculated by dividing the number of correctly classified fields for each crop type by the total number of fields classified for that crop type.

We analysed whether there were significant differences between the two classification results based on McNemar's test (McNemar, 1947). In this test, the lack of independent samples is considered by focusing on how each point was either correctly or incorrectly classified in the two classifications being compared. This approach was adopted in the previous studies (e.g. Foody, 2004).

\section{Results and discussion}

\subsection{Acquired data and separability assessments}

The reflectance from OLI is shown in Figure 4. On 20 May, grassland and wheat fields had been covered with vegetation, and at that time a low reflectance at band 4 and high reflectance at band 5 were observed; other fields had been covered with small plants (less than $7 \mathrm{~cm}$ in height), and their reflectance were similar to that of bare soil. Over 
time, the differences in the observed reflectance values in the visible domain became smaller, and on 7 July the spectral patterns of bands 1-4 were similar among crop types. On the other hand, the reflectance values at bands 5-7 were different between the fields. The shortwave infrared reflectance is useful to evaluate the photosynthesis abilities of vegetation (Serbin et al., 2012, Sonobe et al., 2017a). Indeed, beans, beetroot, and maize were under vegetative growth; in particular, the beetroot fields were completely covered with the rosette leaves, while blooming was confirmed in the potato, grass, and wheat fields. Wheat harvesting was finished by 24 August, and the reflectance pattern of wheat was almost the same as bare soil, but the expense of radium made the variance greater. In this study area, chemical treatment was conducted over the potato fields causing plants to die and make harvesting easier. This treatment made the reflectance at band 5 smaller. Similar spectral features with low reflectance in the visible domain and peaks at band 5 were confirmed for other crops.

$<$ Figure 4. Distributions of reflectance from OLI on the three dates. $>$ A dendrogram based on the correlation relationship of reflectance and spectral indices is shown in Figure 5. The correlations between band 5 and other bands were relatively weak compared with the other combinations. Generally, the improved versions of Normalized Difference Vegetation Index (NDVI), Enhanced Vegetation Index (EVI), or Soil-adjusted Vegetation Index (SAVI) correlated with each other. $<$ Figure 5. Dendrogram based on the correlation relationship of reflectance and spectral indices. $>$

Separability analysis is important to assess the performance of training data, and the separability levels of crop cover pairs were evaluated based on the J-M distances (Table 3). Using the metrics calculated from Landsat 8 OLI data, the J-M distances greater than 1.4 were confirmed, except for the combination of beans and maize. 
However, when only the original reflectance data were applied, J-M distances were lower than 1.4 for the combinations of beans-beetroot, beans-maize, beetroot-maize, and maize-potato. In particular, Norm R, which is expressed as the ratio between Band 4 and the sum of Bands 3, 4, and 5, on 20 May was useful to examine separately. Its high performances were dependant on the ability to distinguish vegetated area and bare soil. Later, Norm R on 7 July (there were no bare soil fields) had low J-M distances, and on 24 August (wheat had already been harvested and the wheat fields were bare soil) had high J-M distances for the combinations. The EVI is sensitive to a higher canopy leaf area index (LAI) and less affected by atmospheric aerosol impacts (Huete et al., 2002); the strong linear relationship with fraction of absorbed photosynthetically active radiation at the biome-specific level was confirmed (Myneni et al., 2002). Furthermore, it can be an indicator for unstressed canopy-level photosynthetic capacity (Sellers et al., 1992). Therefore, it was useful to assess the photosynthesis functions of vegetation when the fields were completely covered with vegetation (i.e. on 7 July), and it could be useful for separating maize and potato.

$<$ Table 3. J-M distance of the top 5 useful metrics for separation between two given crop covers.>

\subsection{Accuracies and statistical comparison}

The summary of accuracy results and McNemar's test results are tabulated in Tables 4 and 5. For all algorithms, OAs more than 0.9 were confirmed, proving good results were achieved. Thus, some ag-specific land cover monitoring programs conducted in the US and Canada (Boryan et al., 2011; Fisette et al., 2013; Wickham et al., 2014) may be useful in our study area. However, the results based on the two improved algorithms (i.e. RF and gcForest) were superior to those of CART. According to AD+QD, RF was the best algorithm for classifying the six crop types and an overall accuracy of $93.6 \%$ 
was achieved. CART archived classifications with high accuracies by classifying fields with a larger sample size than when it was hard to distinguish between two given crop types. The results could show QD values being smaller but $\mathrm{AD}$ values being greater. For all algorithms, classification results were improved by using spectral indices. On the other hand, the advantages of gcForest were not confirmed in this study, and that indicated RF reached its highest degree of accuracy when a single machine learning algorithm was applied. However, the classification results were significantly different between RF and gcForest even though both reflectance and spectral indices were used ( $p<0.05$, based on McNemar’s test), although their accuracies were almost same. Therefore, the theoretical framework for combining classifiers using distinct pattern representations, like the multiple classifier systems (Kittler et al., 1998), should be considered in the future.

< Table 4. Accuracy results for CART, RF, and gcForest.>

< Table 5. Chi-square values from McNemar's test.>

\subsection{Relative importance of the contribution to the RF classification model}

The importance of each metric was evaluated based on VIMP values (Figure 5).

Generally, the data acquired on 24 August was useful for identifying beans, beetroots, and maize, data acquired on 20 May was useful for identifying grass, and data acquired on 9 July was useful for maize and wheat.

On 20 May, the spectral features of beans, beetroots, maize, and potatoes were similar to bare soil due to having small plant bodies, and they were different from those of grass and wheat, which were in their growing season. But the reflectance of grass was higher than that of wheat at band 5-7. The Generalized Difference Vegetation Index (GDVI) values on 20 May for grass and wheat were negative, while those of the other 
crop types were positive; distinguishing between grass and wheat would be easy using SR NIR/SWIR, which is expressed as a simple ratio of the reflectance at band 5 and 7. A positive correlation between shortwave infrared reflectance and leaf nitrogen content has been reported (Bartlett et al., 2011). In this period, wheat plants were in their ripening period and their leaf nitrogen content were decreasing because nitrogen was being used for bearing. That led to the lowest reflectance at bands 6 and 7 on 7 July among all the crop types, and that is why it was the most useful indicator to identify wheat fields. The high reflectance at band 5 was observed for potato fields on the same day, and Hue (based on the differences in reflectance between band 4 and 5) was useful for identifying potato fields. Although the large differences in reflectance between bands 4 and 5 were also confirmed for beans and beetroot fields, the relatively high reflectance at band 6 was helpful to identifying potato fields.

Beetroot was in its growing season, and the plant bodies were completely covering on 24 August and thus a high reflectance at band 5 was confirmed; however, the reflectance at band 6 was the lowest among all the crops. As a result, SCI (the normalized difference between band 5 and 6) on 24 August played the most important role for identifying beetroot. Although the SR NIR/SWIR values of beans and grass were very similar on this date, grassland could be identified based on the data acquired on 20 May. Therefore, SR NIR/SWIR on 24 August was most effective for identifying beans. The maximum rates of carboxylation $\left(V_{c \max }\right)$ and electron transport $\left(J_{\max }\right)$ of C3 plants, which possesses the most efficient photosynthesis functions in cool and wet climates, can be estimated using two narrow bands at shortwave infrared (Sonobe et al., 2017a). However, maize was only a C4 plant, which is most efficient in carrying out photosynthesis in hot and sunny climates; among all the crops, the lowest reflectance 
was observed over maize fields on 24 August, which was in the growing season of maize.

$<$ Figure 5. Variable importance (VIMP) of the top 10 metrics obtained from Landsat 8 OLI data for identifying each crop: (a) beans, (b) beetroot, (c) grass, (d) maize, (e) potato, and (f) wheat.>

\section{Conclusions}

Crop maps, including reflectance and spectral indices, were generated using Landsat 8 OLI data acquired on 20 May, 7 July, and 24 August. Then, the performance of three machine learning algorithms including CART, RF, and gcForest was compared. The classification results based on the two improved algorithms (i.e. RF and gcForest) were superior to those of CART and we found that RF generated the most accurate agricultural land cover maps for the study area.

The most effective metrics determined from Landsat 8 OLI data were SR NIR/SWIR on 24 August for identifying beans fields, SCI on 24 August for identifying beetroot fields, GDVI on 20 May for identifying grassland, the reflectance at band 7 on 24 August for maize fields, Hue on 7 July for identifying potato fields, and the reflectance at band 6 for identifying wheat fields.

The RF classifier using reflectance and spectral indices was found to generate the most accurate crop classification map for the study area, with an overall accuracy of 93.6\%. gcForest, which generates a deep forest ensemble with a cascade structure to do representation learning, was not found to give any advantage over other systems. Although their accuracies were almost same, the classification results were significantly different between RF and gcForest ( $\mathrm{p}<0.05$, based on McNemar's test), and it implied that combined use could offer further improvement on classification accuracies. 


\section{Acknowledgments}

The authors would like to thank Tokachi Nosai for providing the field data. We would like to thank Golden (www.goldenenglishediting.com) for editing and proofreading this manuscript.

\section{Disclosure statement}

No potential conflicts of interest are reported by the authors.

\section{References}

Al-Khaier, F., 2003 Soil salinity detection using satellite remote sensing. Utrecht University.

Allen, W.A., Gausman, H.W., Richardson, A.J. \& Thomas, J.R., 1969. Interaction of isotropic light with a compact plant leaf. Journal of the Optical Society of Americ, 59, 1376-1379.

Ashburn, P., 1978. The vegetative index number and crop identification. The LACIE Symposium Proceedings of the Technical Session, 843-855.

Baig, M.H.A., Zhang, L.F., Shuai, T. \& Tong, Q.X., 2014. Derivation of a tasselled cap transformation based on Landsat 8 at-satellite reflectance. Remote Sensing Letters, 5, 423-431.

Bartlett, M.K., Ollinger, S.V., Hollinger, D.Y., Wicklein, H.F. \& Richardson, A.D., 2011. Canopy-scale relationships between foliar nitrogen and albedo are not observed in leaf reflectance and transmittance within temperate deciduous tree species. Botany-Botanique, 89, 491-497.

Biau, G. \& Scornet, E., 2016. A random forest guided tour. Test, 25, 197-227.

Birth, G.S. \& Mcvey, G.R., 1968. Measuring the Color of Growing Turf with a Reflectance Spectrophotometer. Agronomy Journal, 60, 640-643.

Boryan, C., Yang, Z., Mueller, R., \& Craig, M., 2011. Monitoring US Agriculture: the US Department of Agriculture, National Agricultural Statistics Service, Cropland Data Layer Program. Geocarto International, 26, 341-358.

Breiman, L., 2001. Random forests. Machine Learning, 45, 5-32.

Breiman, L., Friedman, J., Stone, C.J. \& Olshen, R.A., 1984. Classification and Regression Trees London: Taylor \& Francis.

Carter, G.A., 1994. Ratios of leaf reflectances in narrow wavebands as indicators of plant stress. International Journal of Remote Sensing, 15, 697-703.

Chen, J.M. \& Cihlar, J., 1996. Retrieving leaf area index of boreal conifer forests using landsat TM images. Remote Sensing of Environment, 55, 153-162.

Crippen, R.E., 1990. Calculating the vegetation index faster. Remote Sensing of Environment, 34, 71-73.

Cutler, D.R., Edwards, T.C., Beard, K.H., Cutler, A. \& Hess, K.T., 2007. Random forests for classification in ecology. Ecology, 88, 2783-2792. 
Dabney, S.M., Delgado, J.A. \& Reeves, D.W., 2001. Using winter cover crops to improve soil and water quality. Communications in Soil Science and Plant Analysis, 32, 1221-1250.

Dahms, T., Seissiger, S., Borg, E., Vajen, H., Fichtelmann, B. \& Conrad, C., 2016. Important Variables of a RapidEye Time Series for Modelling Biophysical Parameters of Winter Wheat. Photogrammetrie Fernerkundung Geoinformation, 285-299.

Datt, B., 1999. Remote sensing of water content in Eucalyptus leaves. Australian Journal of Botany, 47, 909-923.

Derring, D.W., Rouse, J.W., Haas, R.H. \& Schell, H.H., 1980. Measuring “forage production” of grazing units from Landsat MSS dataed. The Tenth International Symposium of Remote Sensing of the Environment, Ann Arbor, USA, 1169-1198.

Elste, S., Glasser, C., Walther, I. \& Gotze, C., 2015. Multi-temporal Analysis of RapidEye Data to Detect Natural Vegetation Phenology During Two Growing Seasons in the Northern Negev, Israel. Photogrammetrie Fernerkundung Geoinformation, 117-127.

Escadafal, R., Belghith, A. \& Ben Moussa, H., 1994. Indices spectraux pour la degradation des milieux naturels en Tunisie arideed. 6e Symposium international sur les mesures physiques et signatures en teledetection, Val d'Isere, France, 253-259.

Escadafal, R. \& Huete, A., 1991. Improvement in remote sensing of low vegetation cover in arid regions by correcting vegetation indices for soil "noise". Comptes Rendus De L Academie Des Sciences Serie Ii, 312, 1385-1391.

Fensholt, R. \& Sandholt, I., 2003. Derivation of a shortwave infrared water stress index from MODIS near- and shortwave infrared data in a semiarid environment. Remote Sensing of Environment, 87, 111-121.

Fisette, T., Rollin, P., Aly, Z., Campbell, L., Daneshfar, B., Filyer, P., Smith, A., Davidson, A., Shang, J., \& Jarvis, I., 2013. AAFC annual crop inventory, 2013 Second International Conference on Agro-Geoinformatics (AgroGeoinformatics), 270 - 274.

Foody, G.M. \& Mathur, A. 2004. Toward intelligent training of supervised image classifications: directing training data acquisition for SVM classification. Remote Sensing of Environment, 93, 107-117.

Fraser, R.H., Van Der Sluijs, J. \& Hall, R.J., 2017. Calibrating Satellite-Based Indices of Burn Severity from UAV-Derived Metrics of a Burned Boreal Forest in NWT, Canada. Remote Sensing, 9, 279.

Gamon, J.A. \& Surfus, J.S., 1999. Assessing leaf pigment content and activity with a reflectometer. New Phytologist, 143, 105-117.

Gitelson, A.A., Kaufman, Y.J. \& Merzlyak, M.N., 1996. Use of a green channel in remote sensing of global vegetation from EOS-MODIS. Remote Sensing of Environment, 58, 289-298.

Gitelson, A.A., Kaufman, Y.J., Stark, R. \& Rundquist, D., 2002. Novel algorithms for remote estimation of vegetation fraction. Remote Sensing of Environment, 80, 76-87.

Gitelson, A.A., Merzlyak, M.N. \& Chivkunova, O.B., 2001a. Optical properties and nondestructive estimation of anthocyanin content in plant leaves. Photochemistry and Photobiology, 74, 38-45.

Gitelson, A.A., Merzlyak, M.N., Zur, Y., Stark, R. \& Gritz, U., 2001. Non-destructive and remote sensing techniques for estimation of vegetation statused. Third European Conference on Precision Agriculture, Montpellier, France, 301-306. 
Gobron, N., Pinty, B., Verstraete, M.M. \& Widlowski, J.L., 2000. Advanced vegetation indices optimized for up-coming sensors: Design, performance, and applications. Ieee Transactions on Geoscience and Remote Sensing, 38, 2489-2505.

Guan, K.Y., Wu, J., Kimball, J.S., Anderson, M.C., Frolking, S., Li, B., Hain, C.R. \& Lobe, D.B., 2017. The shared and unique values of optical, fluorescence, thermal and microwave satellite data for estimating large-scale crop yields. Remote Sensing of Environment, 199, 333-349.

Hancock, D.W. \& Dougherty, C.T., 2007. Relationships between blue- and red-based vegetation indices and leaf area and yield of alfalfa. Crop Science, 47, 25472556.

Hastie, T., Tibshirani, R. \& Friedman, J., 2009. The Elements of Statistical Learning: Data Mining, Inference, and Prediction. Second Edition The United States: Springer-Verlag New York.

Hewson, R.D., Cudahy, T.J., Huntington, J.F. \& Ieee, 2001. Geologic and alteration mapping at Mt Fitton, South Australia, using ASTER satellite-borne data. Igarss 2001: Scanning the Present and Resolving the Future, Vols 1-7, Proceedings, 724-726.

Huete, A., Didan, K., Miura, T., Rodriguez, E.P., Gao, X. \& Ferreira, L.G., 2002. Overview of the radiometric and biophysical performance of the MODIS vegetation indices. Remote Sensing of Environment, 83, 195-213.

Immitzer, M. \& Atzberger, C., 2014. Early Detection of Bark Beetle Infestation in Norway Spruce (Picea abies, L.) using WorldView-2 Data. Photogrammetrie Fernerkundung Geoinformation, 351-367.

Ishwaran, H. \& Kogalur, U.B., 2007. Random survival forests for R. $R$ News, 7, 25-31.

Ishwaran, H., Kogalur, U.B., Blackstone, E.H. \& S., L.M., 2008. Random survival forests. The Annals of Applied Statistics, 2, 841-860.

Jiang, Z.Y., Huete, A.R., Didan, K. \& Miura, T., 2008. Development of a two-band enhanced vegetation index without a blue band. Remote Sensing of Environment, 112, 3833-3845.

Jin, X.L., Song, K.S., Du, J., Liu, H.J. \& Wen, Z.D., 2017. Comparison of different satellite bands and vegetation indices for estimation of soil organic matter based on simulated spectral configuration. Agricultural and Forest Meteorology, 244, 57-71.

Karnieli, A., Kaufman, Y.J., Remer, L. \& Wald, A., 2001. AFRI - aerosol free vegetation index. Remote Sensing of Environment, 77, 10-21.

Khan, M.R., De Bie, C., Van Keulen, H., Smaling, E.M.A. \& Real, R., 2010. Disaggregating and mapping crop statistics using hypertemporal remote sensing. International Journal of Applied Earth Observation and Geoinformation, 12, 36-46.

Kittler, J., Hatef, M., Duin, R.P.W. \& Matas, J., 1998. On combining classifiers. Ieee Transactions on Pattern Analysis and Machine Intelligence, 20, 226-239.

Lymburner, L., Beggs, P.J. \& Jacobson, C.R., 2000. Estimation of canopy-average surface-specific leaf area using Landsat TM data. Photogrammetric Engineering and Remote Sensing, 66, 183-191.

Malthus, T.J., Andrieu, B., Danson, F.M., Jaggard, K.W. \& Steven, M.D., 1993. Candidate high spectral resolution infrared indices for crop cover. Remote Sensing of Environment, 46, 204-212.

Masemola, C., Cho, M.A. \& Ramoelo, A., 2016. Comparison of Landsat 8 OLI and Landsat 7 ETM+ for estimating grassland LAI using model inversion and 
spectral indices: case study of Mpumalanga, South Africa. International Journal of Remote Sensing, 37, 4401-4419.

Matthew, M.W., Adler-Golden, S.M., Berk, A., Richtsmeier, S.C., Levine, R.Y., Bernstein, L.S., Acharya, P.K., Anderson, G.P., Felde, G.W., Hoke, M.L., Ratkowski, A.J., Burke, H.-H.K., Kaiser, R.D. \& Miller, D.P., 2000. Status of atmospheric correction using a MODTRAN4-based algorithm. In S.S. Shen, Descour, Michael R. (ed.) SPIE 4049, Algorithms for Multispectral, Hyperspectral, and Ultraspectral Imagery VI. Orlando, FL: SPIE-The International Society for Optical Engineering. , 410341.

Mcnemar, Q., 1947. Note on the sampling error of the difference between correlated proportions or percentages. Psychometrika, 12, 153-157.

Metternicht, G., 2003. Vegetation indices derived from high-resolution airborne videography for precision crop management. International Journal of Remote Sensing, 24, 2855-2877.

Miura, T., Huete, A.R., Van Leeuwen, W.J.D. \& Didan, K., 1988. Vegetation detection trough smoke-filled AVIRIS images: an assessment using MODIS band passes. Journal of Geophysical Research, 103, 32001-32011.

Miura, T., Yoshioka, H., Fujiwara, K. \& Yamamoto, H., 2008. Inter-comparison of ASTER and MODIS surface reflectance and vegetation index products for synergistic applications to natural resource monitoring. Sensors, 8, 2480-2499.

Myneni, R.B., Hoffman, S., Knyazikhin, Y., Privette, J.L., Glassy, J., Tian, Y., Wang, Y., Song, X., Zhang, Y., Smith, G.R., Lotsch, A., Friedl, M., Morisette, J.T., Votava, P., Nemani, R.R. \& Running, S.W., 2002. Global products of vegetation leaf area and fraction absorbed PAR from year one of MODIS data. Remote Sensing of Environment, 83, 214-231.

Pastor-Guzman, J., Atkinson, P.M., Dash, J. \& Rioja-Nieto, R., 2015. Spatiotemporal Variation in Mangrove Chlorophyll Concentration Using Landsat 8. Remote Sensing, 7, 14530-14558.

Perry Jr, C.R. \& Lautenschlager, L.F., 1984. Functional equivalence of spectral vegetation indices. Remote Sensing of Environment, 14, 169-182.

Pontius, R. \& Millones, M., 2011. Death to Kappa: birth of quantity disagreement and allocation disagreement for accuracy assessment. International Journal of Remote Sensing, 32, 4407-4429.

Qi, J., Chehbouni, A., Huete, A.R., Kerr, Y.H. \& Sorooshian, S., 1994. A modified soil adjusted vegetation index. Remote Sensing of Environment, 48, 119-126.

Richards, J.A., 1999. Remote Sensing Digital Image Analysis: Berlin: Springer-Verlag.

Richardson, A.D., Duigan, S.P. \& Berlyn, G.P., 2002. An evaluation of noninvasive methods to estimate foliar chlorophyll content. New Phytologist, 153, 185-194.

Richardson, A.J. \& Wiegand, C.L., 1978. Distinguishing Vegetation from Soil Background Information. Photogrammetric Engineering and Remote Sensing, 43, 1541-1552.

Rondeaux, G., Steven, M. \& Baret, F., 1996. Optimization of soil-adjusted vegetation indices. Remote Sensing of Environment, 55, 95-107.

Rowan, L.C. \& Mars, J.C., 2003. Lithologic mapping in the Mountain Pass, California area using Advanced Spaceborne Thermal Emission and Reflection Radiometer (ASTER) data. Remote Sensing of Environment, 84, 350-366.

Sellers, P.J., Berry, J.A., Collatz, G.J., Field, C.B. \& Hall, F.G., 1992. Canopy reflectance, photosynthesis, and transpiration. III. A reanalysis using improved leaf models and a new canopy integration scheme. Remote Sensing of Environment, 42, 187-216. 
Serbin, S.P., Dillaway, D.N., Kruger, E.L. \& Townsend, P.A., 2012. Leaf optical properties reflect variation in photosynthetic metabolism and its sensitivity to temperature. Journal of Experimental Botany, 63, 489-502.

Sonobe, R., Miura, Y., Sano, T. \& Horie, H., 2018. Estimating leaf carotenoid contents of shade grown tea using hyperspectral indices and PROSPECT-D inversion. International Journal of Remote Sensing, 39, 1306-1320.

Sonobe, R., Tani, H., Wang, X., Kobayashi, N. \& Shimamura, H., 2014. Random forest classification of crop type using multi- temporal TerraSAR- X dual- polarimetric data. Remote Sensing Letters, 5, 157-164.

Sonobe, R., Tani, H. \& Wang, X.F., 2017a. An experimental comparison between KELM and CART for crop classification using Landsat-8 OLI data. Geocarto International, 32, 128-138.

Sonobe, R., Yamaya, Y., Tani, H., Wang, X., Kobayashi, N. \& Mochizuki, K.-I., 2017b. Mapping crop cover using multi-temporal Landsat 8 OLI imagery. International Journal of Remote Sensing, 38, 4348-4361.

Sonobe, R., Yamaya, Y., Tani, H., Wang, X., N., K. \& Mochizuki, K., 2017c. Assessing the Suitability of Data from Sentinel-1A and 2A for Crop Classification. GIScience \& Remote Sensing, 54, 918-938.

Story, M. \& Congalton, R., 1986. Accuracy assessment: A user's perspective. Photogmmmetric Engineering \& Remote Sensing, 52, 397-399.

Thenkabail, P.S., Smith, R.B. \& De Pauw, E., 2002. Evaluation of narrowband and broadband vegetation indices for determining optimal hyperspectral wavebands for agricultural crop characterization. Photogrammetric Engineering and Remote Sensing, 68, 607-621.

Tian, Y., Zhu, Y. \& Cao, W., 2005. Monitoring soluble sugar, total nitrogen \& its ratio in wheat leaves with canopy spectral reflectance. Acta Agronomica sinica, 31, 355-360.

Tucker, C.J., 1979. Monitoring corn and soybean crop development with hand-held radiometer spectral data. Remote Sensing of Environment, 8, 237-248.

Vincini, M., Frazzi, E. \& D'alessio, P., 2008. A broad-band leaf chlorophyll vegetation index at the canopy scale. Precision Agriculture, 9, 303-319.

Vogelmann, J.E., Gallant, A.L., Shi, H. \& Zhu, Z., 2016. Perspectives on monitoring gradual change across the continuity of Landsat sensors using time-series data. Remote Sensing of Environment, 185, 258-270.

Volesky, J.C., Stern, R.J. \& Johnson, P.R., 2003. Geological control of massive sulfide mineralization in the Neoproterozoic Wadi Bidah shear zone, southwestern Saudi Arabia, inferences from orbital remote sensing and field studies. Precambrian Research, 123, 235-247.

Wang, F., Huang, J.-F. \& Chen, L., 2010. New Vegetation Index and Its Application in Estimating Leaf Area Index of Rice. Journal of Plant Nutrition, 33, 328-33.

Wang, F.-M., Huang, J.-F., Tang, Y.-L. \& Wang, X.-Z., 2007. New Vegetation Index and Its Application in Estimating Leaf Area Index of Rice. Rice Science, 14, 195-203.

Wickham, J. Homer, C. Vogelmann, J. McKerrow, A. Mueller, R. Herold, N. Coulston, J. 2014. The Multi-Resolution Land Characteristics (MRLC) Consortium: 20 years of development and integration of USA national land cover data. Remote Sensing, 6, 7424-7441.

Wulder, M.A., White, J.C., Goward, S.N., Masek, J.G., Irons, J.R., Herold, M., Cohen, W.B., Loveland, T.R. \& Woodcock, C.E., 2008. Landsat continuity: Issues and 
opportunities for land cover monitoring. Remote Sensing of Environment, 112, 955-969.

Zarco-Tejada, P.J., Berjon, A., Lopez-Lozano, R., Miller, J.R., Martin, P., Cachorro, V., Gonzalez, M.R. \& De Frutos, A., 2005. Assessing vineyard condition with hyperspectral indices: Leaf and canopy reflectance simulation in a rowstructured discontinuous canopy. Remote Sensing of Environment, 99, 271-287.

Zhou, Z.H. \& Feng, J., 2017. Deep forest: Towards an alternative to deep neural networks. arXiv:1702.08835v1. 


\section{Table}

Table 1. Cultivation calendar for the crops.

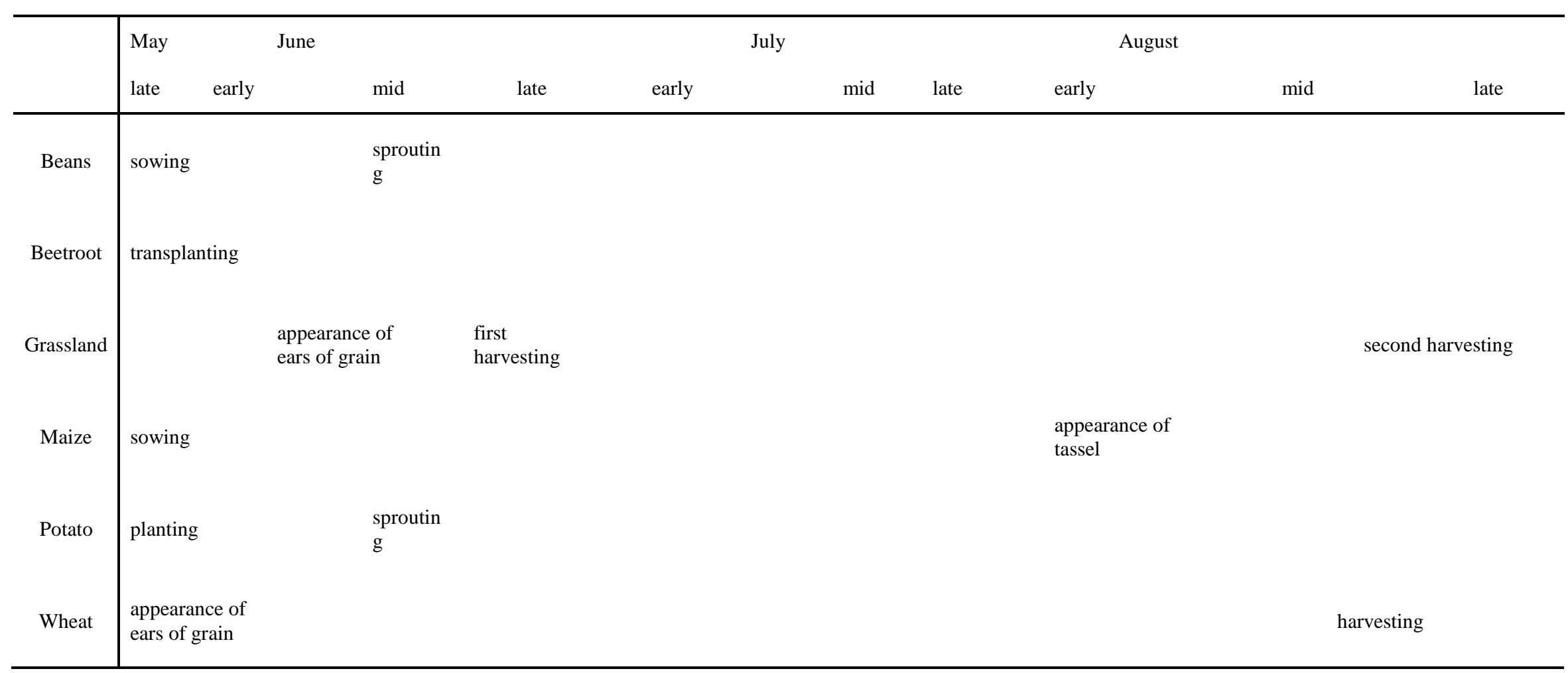


Table 2. Spectral indices used in this study.

\begin{tabular}{|c|c|c|}
\hline Index & Formula & Literature \\
\hline AFRI1.6 & $\frac{\text { Band } 5-0.66 * \text { Band } 6}{\text { Band } 5+0.66 * \text { Band } 6}$ & Karnieli et al. (2001) \\
\hline AVI & $2.0 *$ Band $5-$ Band 4 & Ashburn (1978) \\
\hline BGI & $\frac{\text { Band1 }}{\text { Band3 }}$ & $\begin{array}{l}\text { Zarco-Tejada et al. } \\
\text { (2005) }\end{array}$ \\
\hline BNDVI & $\frac{\text { Band } 5-\text { Band } 2}{\text { Band } 5+\text { Band } 2}$ & Wang et al. (2007) \\
\hline BWDRVI & $\frac{0.1 * \text { Band } 5-\text { Band } 2}{0.1 * \text { Band } 5+\text { Band } 2}$ & $\begin{array}{l}\text { Hancock and Dougherty } \\
\text { (2007) }\end{array}$ \\
\hline CRI550 & 1/Band $2-1 /$ Band 3 & Gitelson et al. (2001a) \\
\hline CVI & Band5 $* \frac{\text { Band } 4}{\text { Band } 32^{2}}$ & Vincini et al. (2008) \\
\hline DVI & $\frac{\text { Band5 }}{\text { Band4 }}$ & $\begin{array}{l}\text { Birth and McVey } \\
\text { (1968) }\end{array}$ \\
\hline EVI & $2.5 * \frac{\text { Band } 5-\text { Band } 4}{\text { Band } 5+6 * \text { Band } 4-7.5 * \text { Band } 2+1}$ & Huete et al. (2002) \\
\hline EVI2 & $2.4 * \frac{\text { Band } 5-\text { Band } 4}{\text { Band } 5+\text { Band } 4+1}$ & Miura et al. (2008) \\
\hline EVI3 & $2.5 * \frac{\text { Band } 5-\text { Band } 4}{\text { Band } 5+2.4 * \text { Band } 4+1}$ & Jiang et al. (2008) \\
\hline $\mathrm{Fe} 2$ & $\frac{\text { Band7 }}{\text { Band } 5}+\frac{\text { Band } 3}{\text { Band } 4}$ & Rowan and Mars (2003) \\
\hline GARI & $\frac{\text { Band } 5-(\text { Band } 3-(\text { Band } 2-\text { Band } 4))}{B \text { Band } 5-(\text { Band } 3+(\text { Band } 2-\text { Band } 4))}$ & Gitelson et al. (1996) \\
\hline GBNDVI & $\frac{\text { Band } 5-(\text { Band } 3+\text { Band } 2)}{\text { Band } 5+(\text { Band } 3+\text { Band } 2)}$ & Wang et al. (2010) \\
\hline GDVI & Band4 - Band3 & Tucker (1979) \\
\hline GLI & $\frac{2 * \text { Band } 3-\text { Band } 4-\text { Band } 2}{2 * \text { Band } 3+\text { Band } 4-\text { Band } 2}$ & Gobron et al. (2000) \\
\hline GNDVI & $\frac{\text { Band } 5-\text { Band } 3}{\text { Band } 5+\text { Band } 3}$ & Gitelson et al. (1996) \\
\hline
\end{tabular}


GOSAVI

Gossan

GRNDVI

GRVI

GSAVI

Hue

I

IF

IO

IPVI

MNDVI

MSAVI

MSRNIR/Red

MVI

NDSI

Norm G

Norm NIR
Band5 - Band3

$\overline{\text { Band5 }- \text { Band } 3+0.16}$

Rondeaux et al. (1996)

Volesky et al. (2003)

$\frac{\text { Band } 5-(\text { Band } 3+\text { Band } 4)}{\text { and } 5+(\text { Band } 3+\text { Band } 4)}$

Wang et al. (2007)

Gitelson et al. (2002)

Band3

$1.5 * \frac{\text { Band } 5-\text { Band } 3}{\text { Band } 5+\text { Band } 3+0.5}$

Tian et al. (2005)

$\operatorname{atan}\left(\frac{2 * \text { Band } 4-\text { Band } 3-\text { Band } 2}{30.5} *(\right.$ Band $3-$ Band 2$\left.)\right)$

$\frac{\text { Band } 4+\text { Band } 3+\text { Band } 2}{30.5}$

30.5

Escadafal et al. (1994)

$\frac{2 * \text { Band } 4-\text { Band } 3-\text { Band } 2}{\text { Band } 3-\text { Band } 2}$

Band4

$\overline{\text { Band } 1}$

$2 * \frac{\text { Band } 5}{\text { Band } 5+\text { Band } 4}\left(\frac{\text { Band } 4-\text { Band } 3}{\text { Band } 4+\text { Band } 3}+1\right)$

Crippen (1990)

Miura et al. (1988)

$\overline{\text { Band5 + Band } 7}$

$\frac{2 * \text { Band } 5+1-\sqrt{(2 * \text { Band } 5+1)^{2}-8 *(\text { Band } 5-\text { Band } 4)}}{2}$

Qi et al. (1994)

Chen and Cihlar (1996)

$$
\frac{\frac{\text { Band } 5}{\text { Band4 }}-1}{\sqrt{\left(\frac{\text { Band } 5}{\text { Band } 4}+1\right)}}
$$

Band5

$\overline{\text { Band6 }}$

Thenkabail et al. (2002)

Band 6-Band 7

$\overline{\text { Band6 + Band } 7}$

Richardson et al. (2002)

$\frac{\text { Band3 }}{\text { Band } 5+\text { Band } 4+\text { Band } 3}$

Band5

Fraser et al. (2017)

$\frac{\text { Band } 5}{\text { Band } 5+\text { Band } 4+\text { Band } 3}$


Norm R

PNDVI

PPR

PVR

RBNDVI

RGR

RI

SBL

SCI

SIWSI

SLAVI

SR(550,670)

SR NIR/SWIR

SR $(1650,2218)$

$$
\text { Band } 5-2.4 * \text { Band } 4
$$

$$
\frac{\text { Band } 6-\text { Band } 5}{\text { Band } 6+\text { Band } 5}
$$$$
\text { Band5 - Band6 }
$$$$
\overline{\text { Band5 + Band6 }}
$$

$$
\frac{\text { Band5 }}{\text { Band } 4+\text { Band } 7}
$$

$$
\frac{\text { Band3 }}{B a n d 4}
$$

Band5

Band 7

\section{Band6}

Band 7
Wang et al. (2007)

Metternicht (2003)

Wang et al. (2007)

Gamon and Surfus,

Escadafal and Huete,

Richardson and

Wiegand (1978)

Al-Khaier (2003)

Fensholt and Sandholt

(2003)

Lymburner et al. (2000)

Carter (1994)

Malthus et al. (1993)

Datt (1999)

$$
0.3029 * \text { Band } 2+0.2786 * \text { Band } 3+0.4733 * \text { Band } 4
$$

$$
\begin{aligned}
& +0.5599 * \text { Band } 5+0.5080 * \text { Band } 6+0.1872 * \text { Band } 7 \\
& -0.2941 * \text { Band } 2-0.2430 * \text { Band } 3-0.5424 * \text { Band } 4
\end{aligned}
$$

Baig et al. (2014)

TC2

$$
+0.7276 * \text { Band } 5+0.0713 * \text { Band } 6-0.1608 * \text { Band } 7
$$


TC3

$$
0.1511 * \text { Band } 2+0.1973 * \text { Band } 3+0.3283 * \text { Band } 4
$$

$+0.3407 *$ Band $5-0.7117 *$ Band $6-0.4559 *$ Band7

$-0.8239 *$ Band $2+0.0849 *$ Band $3+0.4396 *$ Band 4

TC4

$-0.0580 *$ Band $5+0.2013 *$ Band $6-0.2773 *$ Band7

$-0.3294 *$ Band $2+0.0557 *$ Band $3+0.1056 *$ Band 4

TC5

$+0.1855 *$ Band $5-0.4349 *$ Band $6+0.8085 *$ Band7

$0.1079 *$ Band $2-0.9023 *$ Band $3+0.4119 *$ Band 4

TC6

$+0.0575 *$ Band $5-0.0259 *$ Band $6+0.0252 *$ Band7

TNDVI

$$
\sqrt{\frac{\text { Band } 5-\text { Band } 4}{\text { Band } 5+\text { Band } 4}+0.5}
$$

Derring et al. (1975)

TVI

$$
(\mathrm{NDVI}+0.5) /|\mathrm{NDVI}+0.5| * \sqrt{|\mathrm{NDVI}+0.5|}
$$

Perry Jr and

Lautenschlager (1984)

VARIgreen

Band3 - Band4

Gitelson et al.

$\overline{\text { Band3 + Band 4-Band2 }}$

(2001b) 
Table 3. J-M distance of the top 5 useful metrics for separation between given two crop covers.

\begin{tabular}{|c|c|c|c|c|c|c|c|c|}
\hline & \multicolumn{2}{|l|}{ Beans-Beetroot } & \multicolumn{2}{|l|}{ Beans-Grass } & \multicolumn{2}{|l|}{ Beans-Maize } & \multicolumn{2}{|l|}{ Beans-Potato } \\
\hline 1 & July07_SIWSI & 1.49 & May20_MSAVI & 1.86 & $\begin{array}{l}\text { Aug24_SR } \\
(1650,2218)\end{array}$ & 1.07 & July07_MSAVI & 1.84 \\
\hline 2 & July07_SCI & 1.49 & May20_EVI2 & 1.85 & Aug24_Gossan & 0.83 & July07_EVI & 1.82 \\
\hline 3 & $\begin{array}{l}\text { Aug24_SR } \\
(1650,2218)\end{array}$ & 1.48 & May20_GOSAVI & 1.85 & Aug24_Fe2 & 0.81 & July07_EVI22 & 1.82 \\
\hline 4 & July07_MNDVI & 1.47 & May20_GSAVI & 1.85 & Aug24_SR(550,670) & 0.54 & July07_EVI2 & 1.82 \\
\hline \multirow[t]{2}{*}{5} & July07_MVI & 1.44 & May20_EVI & 1.85 & Aug24_CVI & 0.49 & July07_GSAVI & 1.81 \\
\hline & \multicolumn{2}{|l|}{ Beans-Wheat } & \multicolumn{2}{|l|}{ Beetroot-Grass } & \multicolumn{2}{|l|}{ Beetroot-Maize } & \multicolumn{2}{|l|}{ Beetroot-Potato } \\
\hline 1 & May20_Norm R & 1.99 & May20_MSAVI & 1.83 & Aug24_BGI & 1.40 & Aug24_MVI & 1.70 \\
\hline 2 & May20_RBNDVI & 1.98 & May20_GSAVI & 1.82 & Aug24_TC6 & 1.35 & $\begin{array}{l}\text { Aug24_SR } \\
\text { NIR/SWIR }\end{array}$ & 1.63 \\
\hline 3 & May20_PNDVI & 1.98 & May20_GOSAVI & 1.81 & Aug24_PPR & 1.10 & Aug24_SLAVI & 1.51 \\
\hline 4 & May20_GRNDVI & 1.98 & May20_EVI2 & 1.81 & July07_MVI & 1.07 & Aug24_Band 5 & 1.51 \\
\hline \multirow[t]{2}{*}{5} & May20_Norm NIR & 1.98 & May20_EVI & 1.81 & Aug24_Fe2 & 1.05 & Aug24_AVI & 1.49 \\
\hline & \multicolumn{2}{|l|}{ Beetroot-Wheat } & \multicolumn{2}{|l|}{ Grass-Maize } & \multicolumn{2}{|l|}{ Grass-Potato } & \multicolumn{2}{|l|}{ Grass-Wheat } \\
\hline 1 & Aug24_VARIgreen & 1.99 & May20_MSAVI & 1.73 & May20_MSAVI & 1.83 & Aug24_RGR & 1.79 \\
\hline 2 & Aug24_PVR & 1.99 & May20_EVI2 & 1.72 & May20_EVI2 & 1.82 & Aug24_VARIgreen & 1.77 \\
\hline 3 & Aug24_RI & 1.99 & May20_EVI22 & 1.71 & May20_EVI & 1.82 & Aug24_PVR & 1.76 \\
\hline 4 & Aug24_RGR & 1.99 & May20_EVI & 1.71 & May20_GSAVI & 1.82 & Aug24_RI & 1.76 \\
\hline 5 & Aug24_GLI & 1.99 & May20_GSAVI & 1.70 & May20_RGR & 1.82 & Aug24_Norm R & 1.76 \\
\hline \multicolumn{3}{|c|}{ Maize-Potato } & \multicolumn{2}{|l|}{ Maize-Wheat } & \multicolumn{2}{|l|}{ Potato-Wheat } & & \\
\hline 1 & July07_MSAVI & 1.49 & May20_Norm R & 1.90 & May20_Norm R & 1.97 & & \\
\hline 2 & July07_EVI & 1.46 & May20_PNDVI & 1.90 & May20_RBNDVI & 1.97 & & \\
\hline 3 & July07_EVI22 & 1.46 & May20_RBNDVI & 1.89 & May20_PNDVI & 1.97 & & \\
\hline 4 & July07_EVI2 & 1.46 & $\begin{array}{l}\text { May20_Norm } \\
\text { NIR }\end{array}$ & 1.89 & May20_Norm NIR & 1.96 & & \\
\hline 5 & July07_AVI & 1.42 & May20_GRNDVI & 1.89 & May20_GRNDVI & 1.96 & & \\
\hline
\end{tabular}


Table 4. Accuracy results for CART, RF and gcForest. PA: producer's accuracy; UA: user’s accuracy; OA: overall accuracy; AD: allocation disagreement; QD: quantity disagreement.

\begin{tabular}{ccccccc}
\hline & \multicolumn{2}{c}{ CART } & \multicolumn{2}{c}{ RF } & \multicolumn{2}{c}{ gcForest } \\
\hline Metrics & $\begin{array}{c}\text { Reflectance } \\
\text { +spectral } \\
\text { indices }\end{array}$ & Reflectance & $\begin{array}{c}\text { Reflectance } \\
\text { +spectral } \\
\text { indices }\end{array}$ & Reflectance & $\begin{array}{c}\text { Reflectance } \\
\text { +spectral } \\
\text { indices }\end{array}$ & Reflectance \\
\hline PA & & & & & & \\
Beans & 0.902 & 0.888 & 0.927 & 0.924 & 0.927 & 0.921 \\
Beetroot & 0.927 & 0.902 & 0.939 & 0.930 & 0.935 & 0.928 \\
Grassland & 0.930 & 0.919 & 0.936 & 0.935 & 0.937 & 0.928 \\
Maize & 0.706 & 0.676 & 0.797 & 0.793 & 0.799 & 0.782 \\
Potato & 0.907 & 0.909 & 0.939 & 0.930 & 0.939 & 0.928 \\
Wheat & 0.964 & 0.960 & 0.974 & 0.970 & 0.971 & 0.968 \\
UA & & & & & & \\
Beans & 0.891 & 0.876 & 0.917 & 0.915 & 0.920 & 0.916 \\
Beetroot & 0.934 & 0.924 & 0.956 & 0.954 & 0.959 & 0.951 \\
Grassland & 0.927 & 0.928 & 0.948 & 0.950 & 0.946 & 0.944 \\
Maize & 0.719 & 0.683 & 0.801 & 0.766 & 0.792 & 0.760 \\
Potato & 0.913 & 0.904 & 0.938 & 0.933 & 0.932 & 0.926 \\
Wheat & 0.961 & 0.953 & 0.964 & 0.961 & 0.965 & 0.960 \\
OA & & & & & & \\
AD & 0.914 & 0.904 & 0.936 & 0.931 & 0.935 & 0.928 \\
QD & 0.082 & 0.091 & 0.059 & 0.062 & 0.060 & 0.066 \\
\hline
\end{tabular}


Table 5. Chi-square values from McNemar's test.

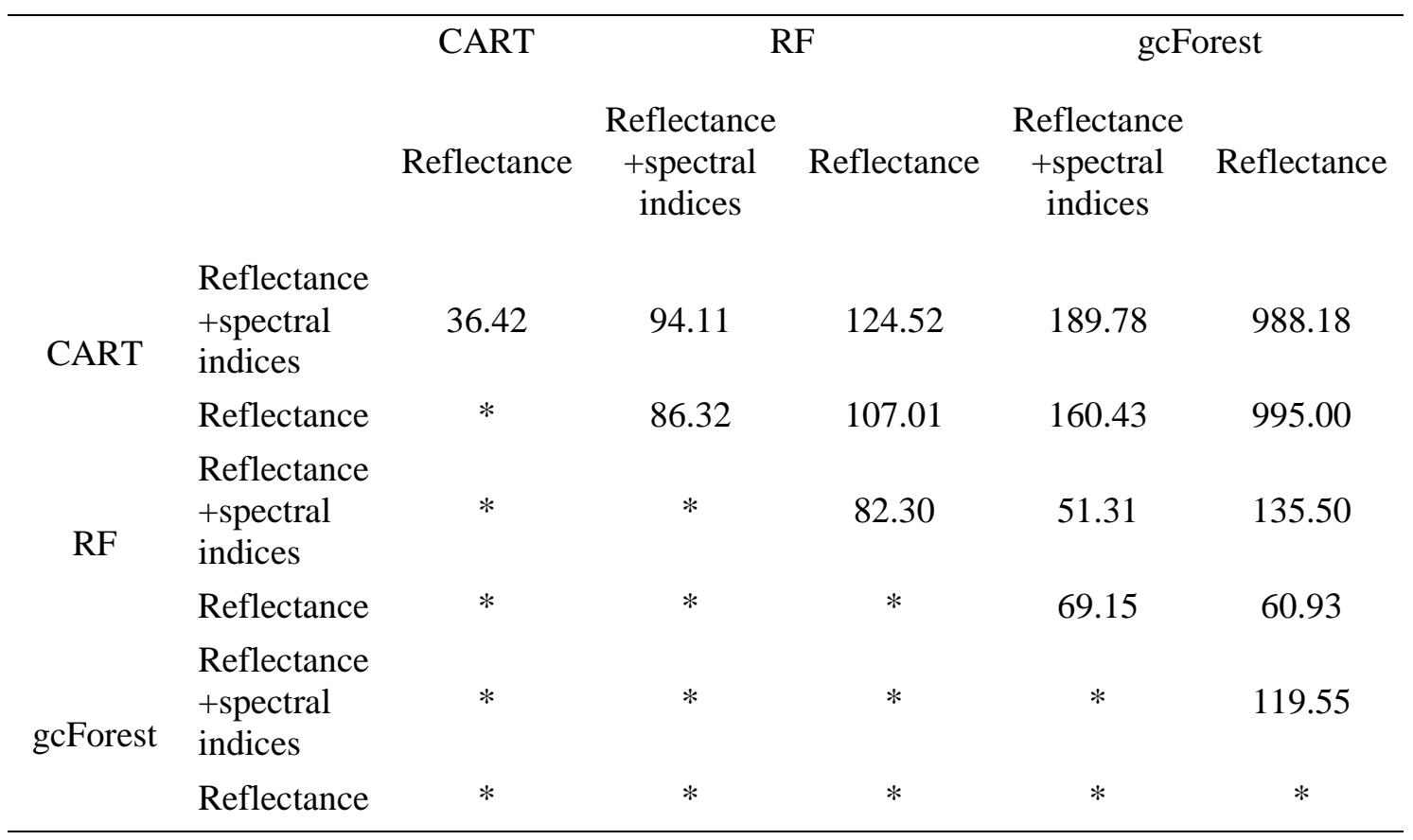




\section{Figure}

Figure 1. The study area and Landsat 8 OLI data acquired on 7 July, 2016 (R: Band 4, G: Band 3, B: Band 2).

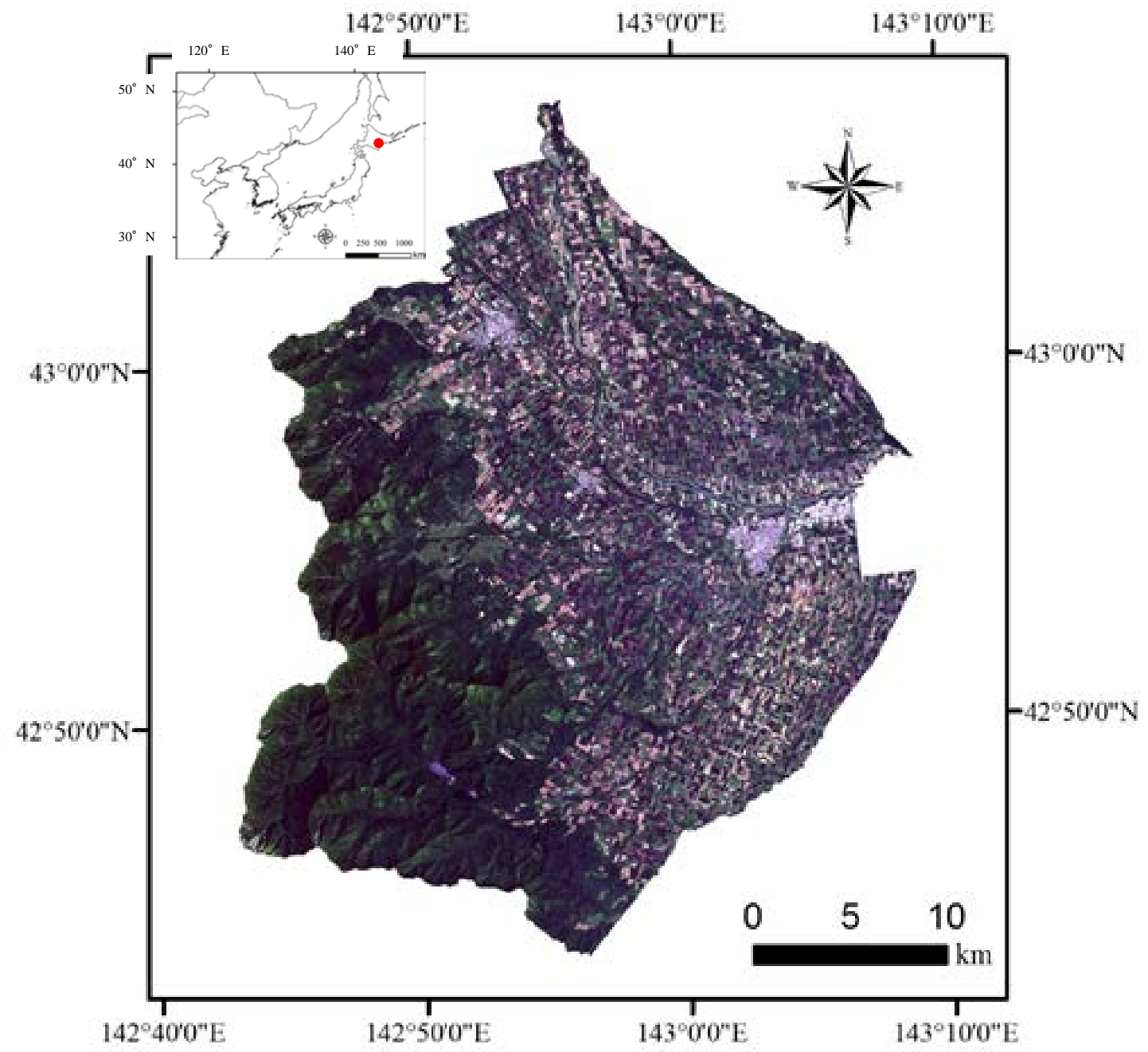


Figure 2. Weather conditions in 2016.

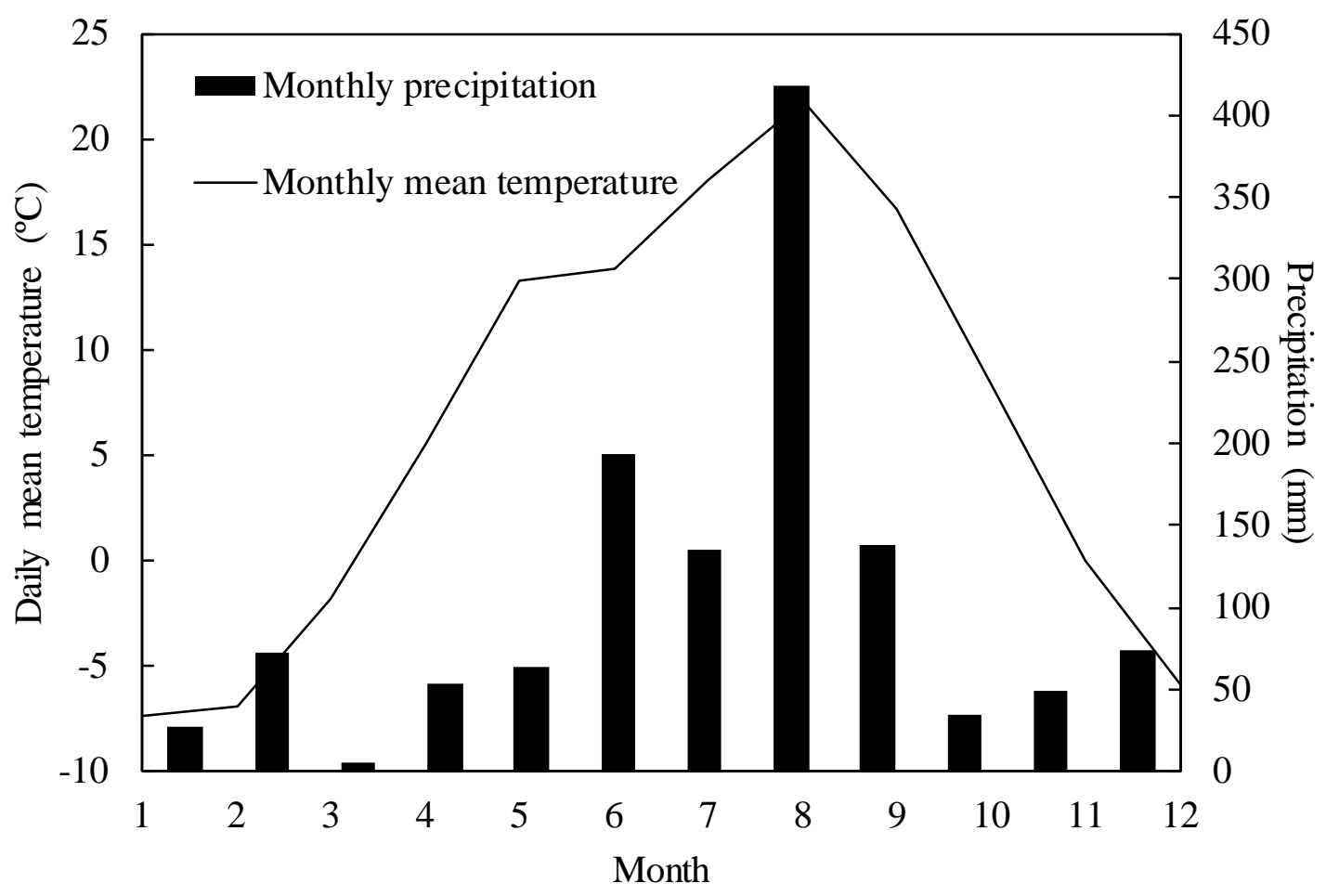


Figure 3. Overview of the data processing.

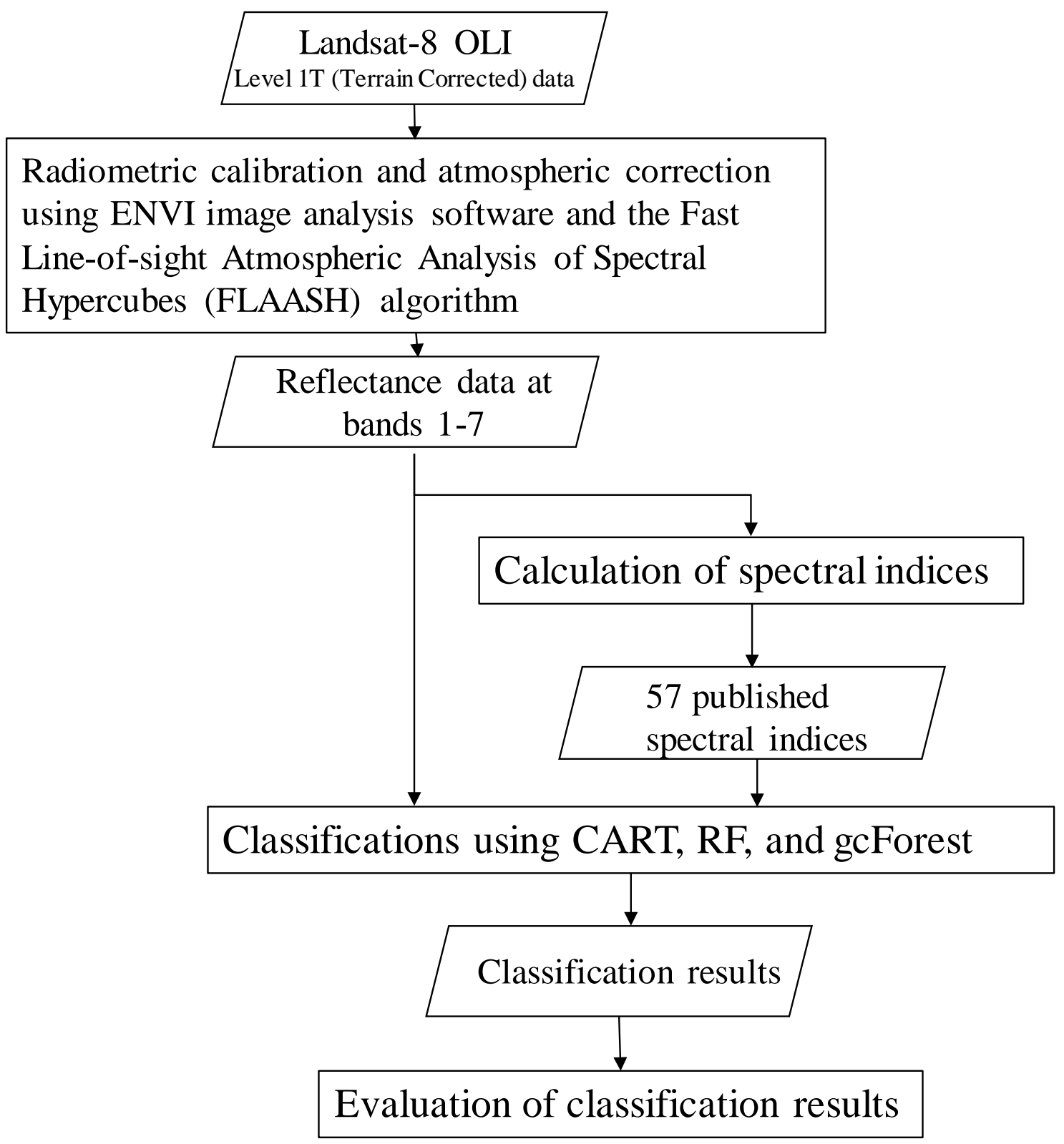


Figure 4.Distributions of reflectance from OLI on the three dates.
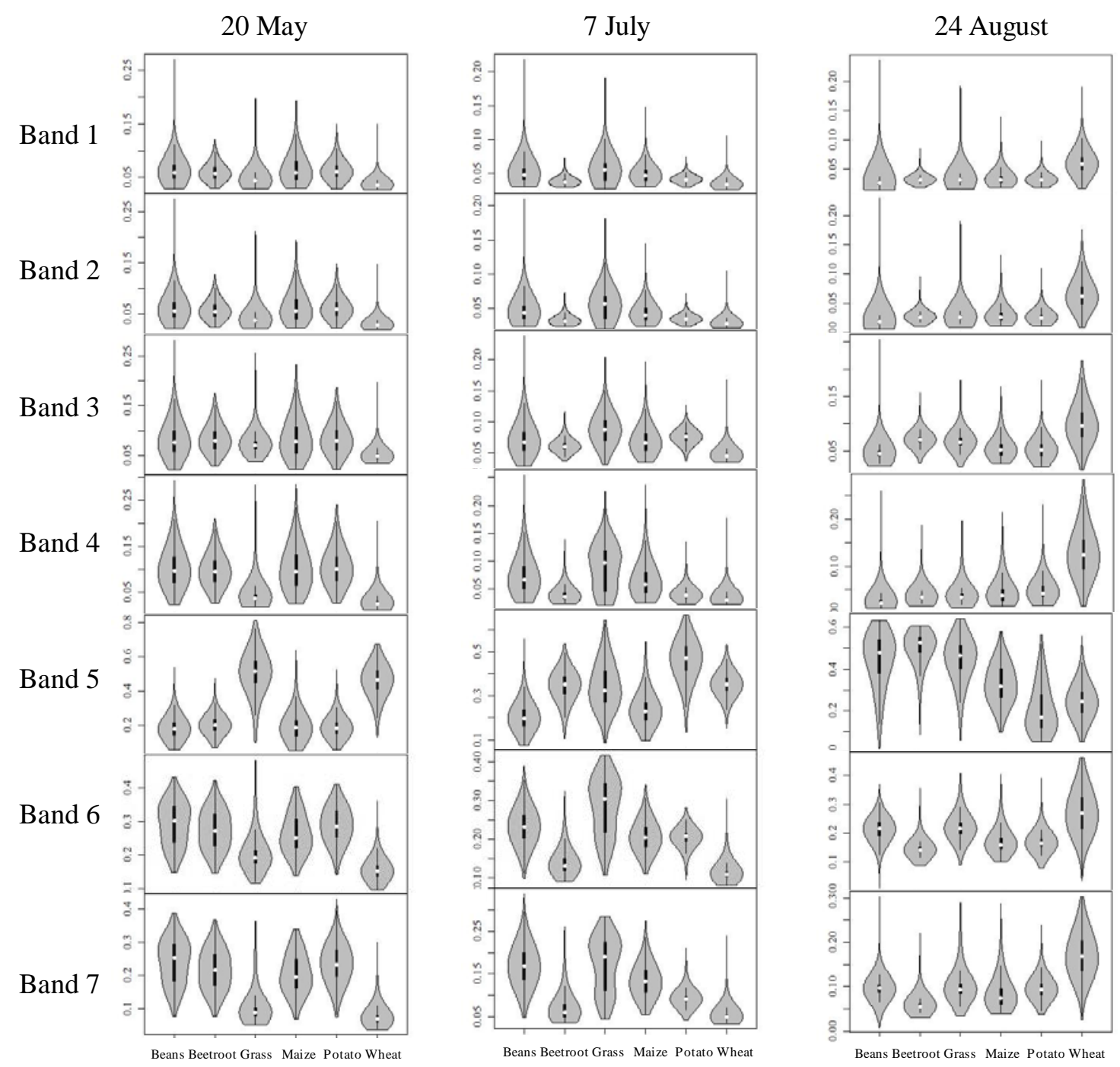
Figure 5. Dendrogram based on the correlation relationship among reflectance and spectral indices.

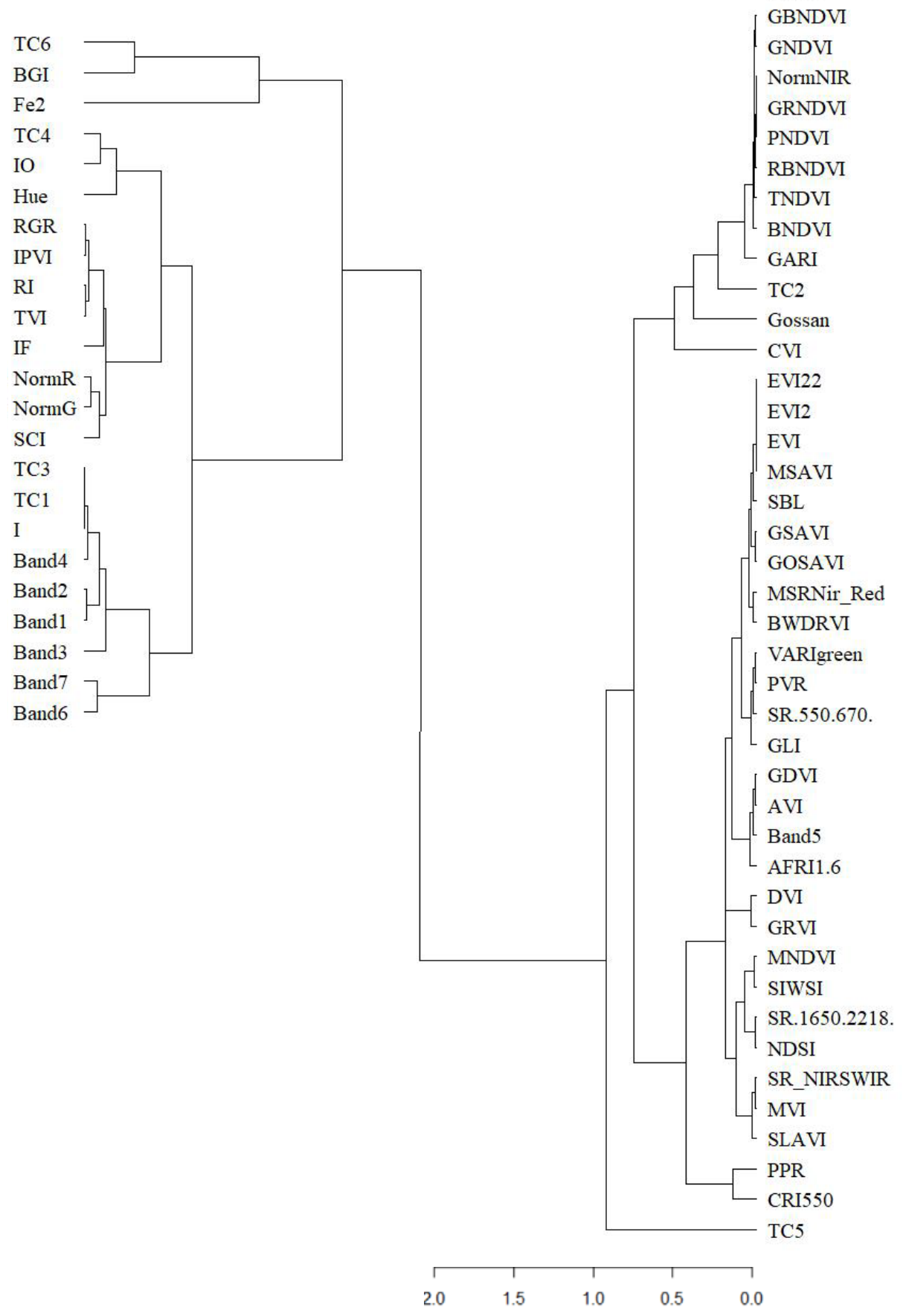


Figure 6. Variable importance (VIMP) of the top 10 metrics obtained from Landsat 8

OLI data for identifying each crop: (a) totally, (b) beans, (c) beetroot, (d) grass, (e) maize, (f) potato, and (g) wheat.
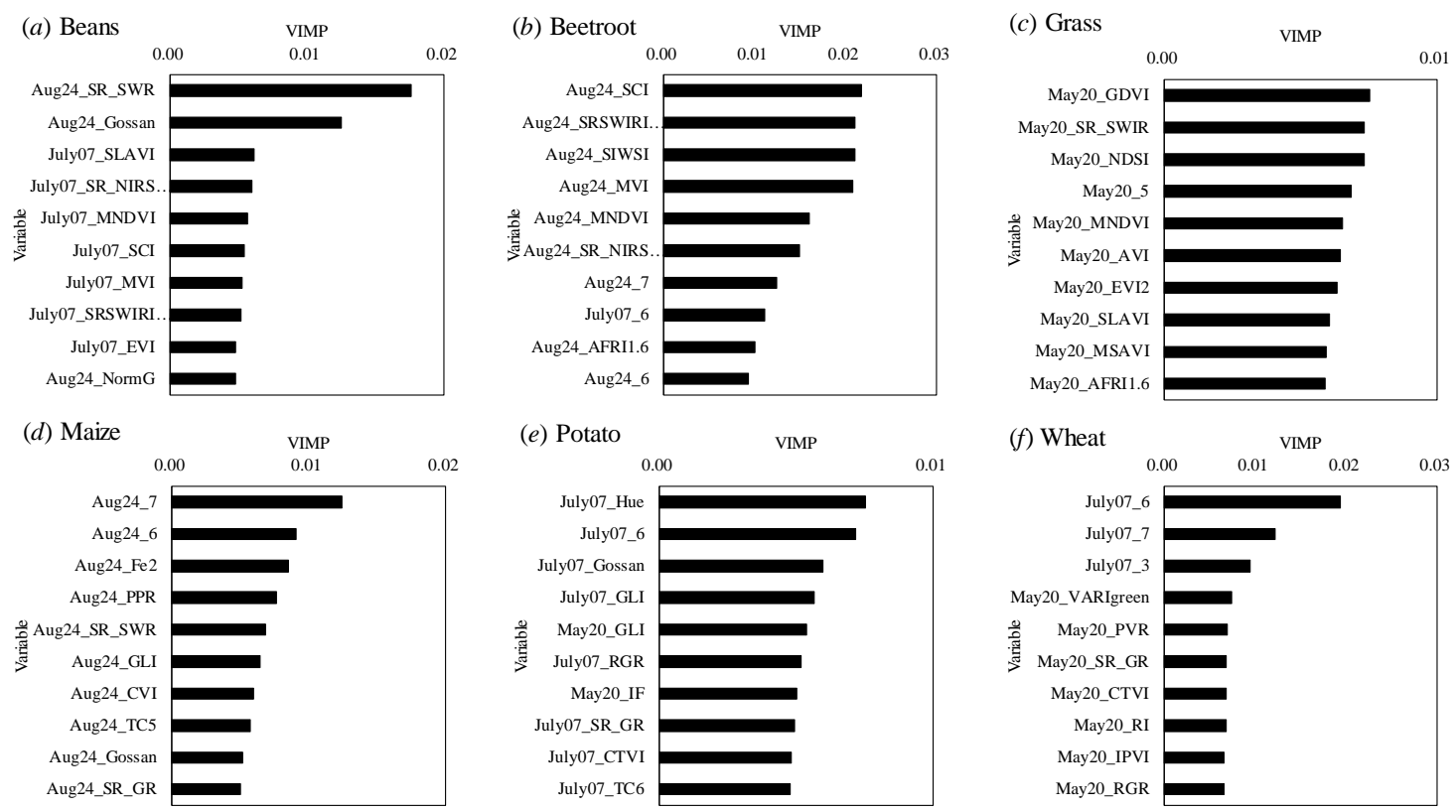